\title{
Demographic profile of Suppurative keratitis
}

\author{
Dr.Bapanapalli Sailaja ${ }^{1,}$ Dr.Bapanapalli Lakshmi ${ }^{2}$ \\ ${ }^{1}$ Assistant Professor of Ophthalmology, Osmania General Hospital, Hyderabad. \\ ${ }^{2}$ Associate Professor of Microbiology, MNR Medical College, Sangareddy.
}

\begin{abstract}
Background: Corneal infections are the second most common cause of ocular blindness due to lack of diagnostic facilities and initiation of appropriate antimicrobial therapy. Suppurative Kerititis is defined as loss of corneal epithelium with underlying stromal infiltration and suppuration associated with signs of inflammation with or without hypopyon. The epidemiological pattern and causative agents for suppurative corneal ulcer varies. It is important to determine the aetiology for comprehensive strategy for the diagnosis and treatment of corneal ulcer.
\end{abstract}

Materials and Methods: This is a prospective study conducted on 819 consecutive patients with clinical diagnosis of suppurative keratitis.

Results: 819 cases with clinical diagnosis of suppurative keratitis were enrolled in this study. A history of previous corneal injury was present in 512 patients $(62.5 \%)$. Central corneal ulcers were found in $680(83 \%)$ patients. Superficial corneal ulcers found in 699(85.3\%) patients. Cornea cultures were positive in 730 patients (89\%). Of those individuals with positive cultures 498 (60.8\%) had pure bacterial infections, $232(28.3 \%)$ had pure fungal infection.In this study of 498 bacterial isolates Staphylococcus.epidermidis 62.2\%, Staph.aureus $32.12 \%$ and Pseudomonas aeroginosa $4 \%$.

Conclusion: Trauma with stick and stone particles was an important cause. Staphylococcus.epidermidis and Staph.aureus were common bacteriological agents. . corneal ulceration is a common problem in India and most often occurs after a superficial corneal injury with organic material. Bacterial infections with Staph.epidermidis accounting for the majority of bacterial ulcers. These findings have important public health implications for the treatment and prevention of corneal ulcer.

Keywords: Trauma with vegetative material, corneal scrapings, culture methods, fluoroquinolones.

\section{Introduction}

The problem of blindness is universal, but the magnitude is much more in India, having 114th the world's total blind population .Out of these, corneal infection is a leading cause of ocular morbidity and blindness world- wide. Bacterial keratitis is one of the most important cause of corneal opacification, which is the second common cause of legal blindness world- wide after cataract. The bacteriological profile in keratitis shows huge disparities amongst populations living both in western and in developing countries...

In our country, one of the most important causes for corneal blindness is infective keratitis caused by various infective agents like bacteria and fungi. Suppurative keratitis or corneal ulcer is due to organisms that produce toxins which cause tissue death and pus formation in the corneal tissue when the ocular defences have been compromised. Suppurative keratitis is nearly always exogenous due to pyogenic bacteria such as Pseudomonas, Staphylococcus aureus and Albus, Pneumococcus . Depending on the characteristics of population and of geographical areas, there is variation in distribution of causative organisms.

Corneal ulcer is defined as a loss of corneal epithelium with underlying stromal infiltration and suppuration associated with signs of inflammation with or without hypopyon. Microbial keratitis in previously normal eye is suspected by the onset of pain and the presence of ulceration, muco purulant exudates adherent to the ulcer surface, focal stromal suppuration, diffuse cellular infiltration in the adjacent stroma and iritis.

This study is done to evaluate the micribiological profile of all suppurative keratitis cases diagnosed at a tertiary eye care center.

\section{Objectives}

A prospective study to evaluate all suppurative keratitis cases enrolled at a tertiary eye care center.

\section{Materials And Methods}

Study design: A Prospective study

Study setting: Department of Ophthalmology, Osmania Medical College and Hospital.

Study population: 819 consecutive patients of Suppurative Keratitis.

Study period: 1 year 


\subsection{Methodology:}

Total of 819 consecutive cases of clinically diagnosed suppurative keratitis, who attended our institute during the study period were included in this study. Inclusion criteria: All culture positive cases, where organism was isolated were analysed. Exclusion criteria:, Typical or suspected Viral ulcers, Healing ulcers, Mooren's ulcers, Marginal keratitis, Interstitial keratitis, Atheromatous ulcer, Neurotrophic ulcer, Any ulcer associated with systemic or autoimmune diseases.

\subsection{Clinical diagnosis:}

A Standardized proforma was filled for each patient. A detailed sociodemografic and clinical history was taken, the visual acuity was measured by standard method - Snellens chart. All patients were examined under Slit - lamp biomicroscope . The morphological features of the ulcer (size, depth of ulcer, margins, hypoyion, satellite lesions, pigmentation over ulcer) were measured after staining with wet sterile fluorescein paper strip and other associated ocular conditions were also noted. Associated systemic and local factors were also checked. Previous treatment history and use of corticosteroids were also noted.

\subsection{Laboratory diagnosis:}

Corneal scraping was done with a sterile Bard-Parker blade (no .15) under topical anaesthesia under strict aseptic conditions. Material was obtained from leading edge and base of each ulcer. For microscopic examination material was smeared on 2 slides for Gram stain and $10 \% \mathrm{KOH}$ mount. For culture material was inoculated on Blood agar, chocolate agar and Sabouraud Dextrose Agar (SDA) plates in a C -shaped streaks. Blood agar and chocolate agar plates were incubated at $37^{\circ} \mathrm{C}$ for 18 to 24 hours aerobically for bacterial culture and discarded after 72 hours if there is no bacterial growth. For fungal culture 2 sets of SDA plates were inoculated and incubated one at $37^{\circ} \mathrm{C}$ and another at Room temperature, examined daily and discarded if no growth was seen after 2 weeks.

Microbial culture was considered positive when there was growth of the same organism on 2 or more media or confluent growth at site of inoculation on one medium and consistent direct microscopy findings or growth of same organism on repeated corneal scraping. Isolates were identified by using standard methods described in Mackie McCartney, .Antibiotic Susceptibility Testing done on Muellar Hinton agar (MHA) with Kirby - Bauer disc diffusion method according to Clinical and Laboratory Standards Institute (CLSI)

\section{Figure No 1}

Disk diffusion method (Kirby-Bauer method)

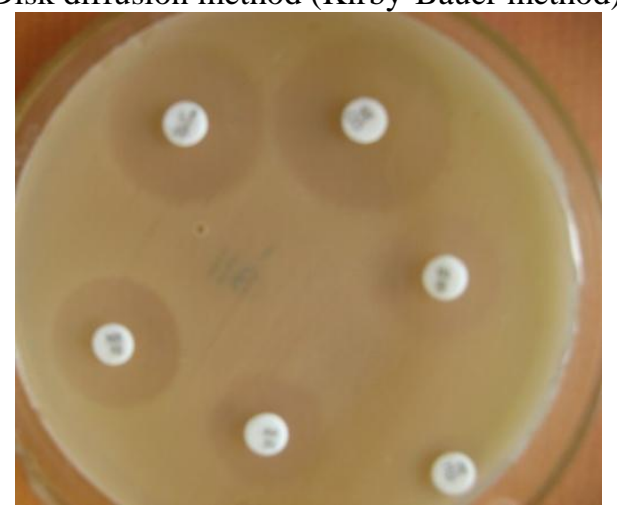

Figure No 2

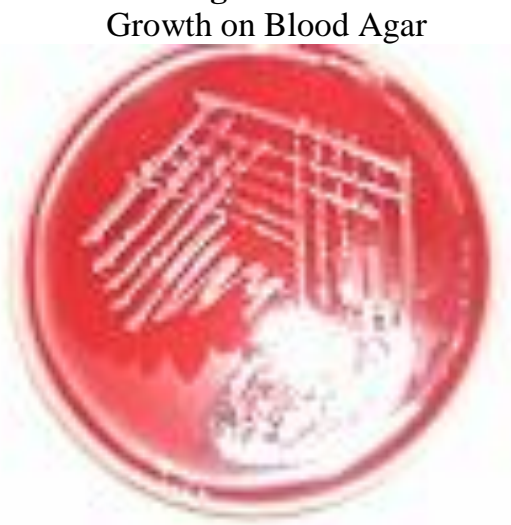




\section{Results}

819 patients with clinical diagnosis of suppurative keratitis were enrolled in this study.

Table No 1

\begin{tabular}{|l|l|l|}
\hline DEMOGRAPHICS & PARTICULARS & $\mathrm{N}(\%)$ \\
\hline SEX & MALE & $501(61.17)$ \\
& FEMALE & $318(38.82)$ \\
\hline AGE IN YEARS & < 10 YEARS & $005(.006)$ \\
& $11-20$ YEARS & $117(14.28)$ \\
\hline & $21-40$ YEARS & $257(31.37)$ \\
& $41-60$ YEARS & $440(53.72)$ \\
\hline
\end{tabular}

Table No 2

\begin{tabular}{|l|l|l|}
\hline DOMICILE & RURAL & $584(71.3)$ \\
& URBAN & $235(28.69)$ \\
\hline OCCUPATION & RURAL LABOUR & $584(71.3)$ \\
& URBAN LABOUR & $141(17.21)$ \\
& OTHERS & $94(11.47)$ \\
\hline
\end{tabular}

Table No 3

\begin{tabular}{|l|l|l|}
\hline EDUCATION & ILLITERATE & $610(74.48)$ \\
& LITERATE & $209(25.51)$ \\
\hline PREDISPOSING FACTORS & TRAUMA & $512(62.51)$ \\
& FOREIGN BODY & $112(13.67)$ \\
& SPONTANEOUS & $195(23.8)$ \\
\hline
\end{tabular}

Morphological Features

Figure No 3

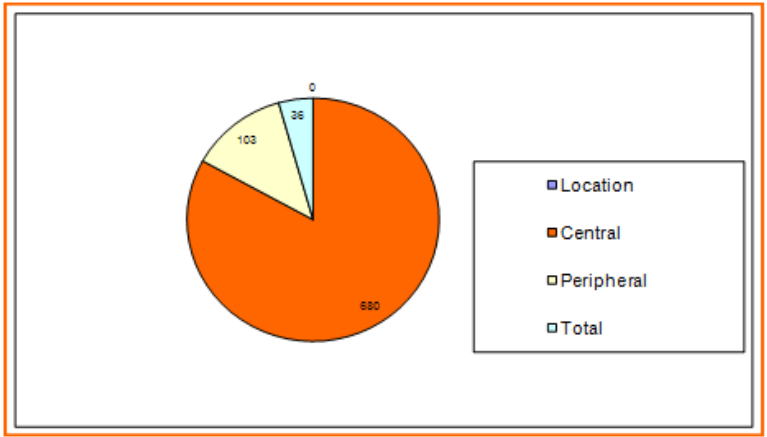

Figure No 4

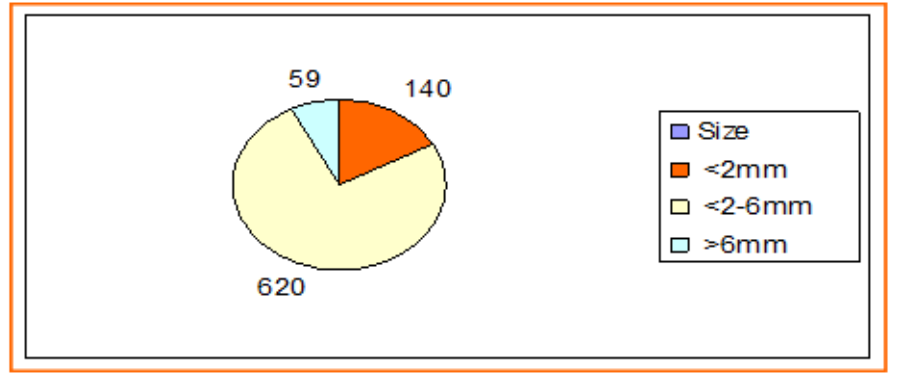

Figure No 5

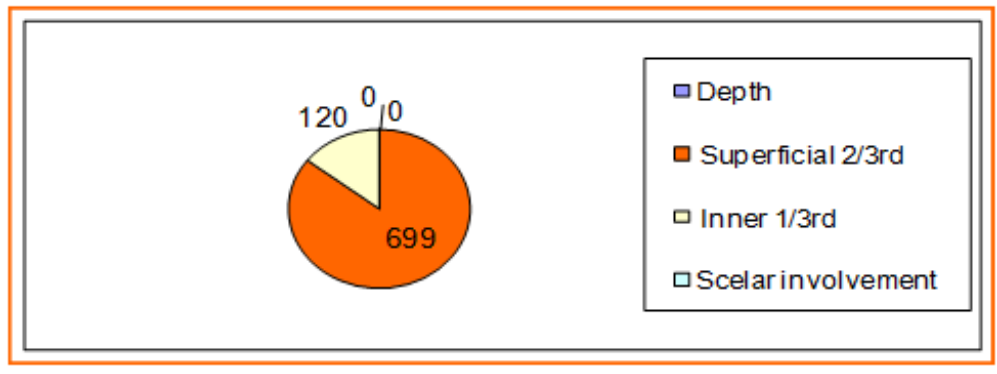




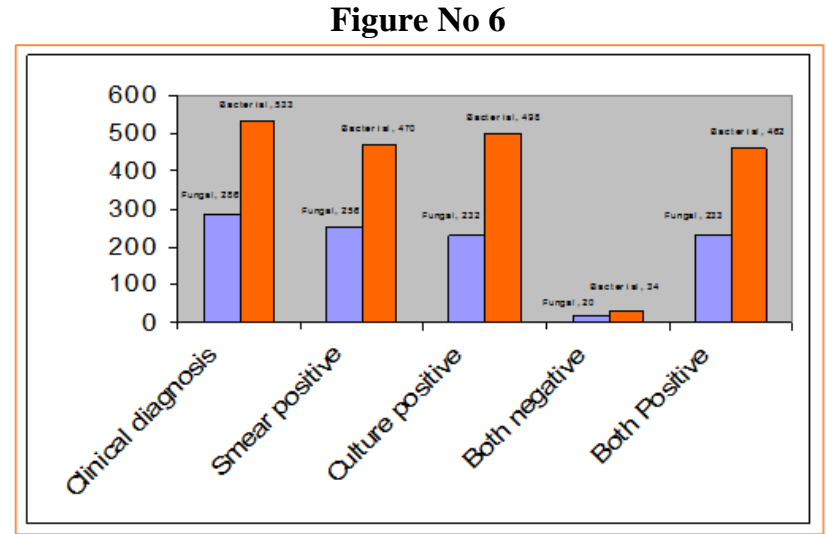

Clinical and final diagnosis

Figure No 7

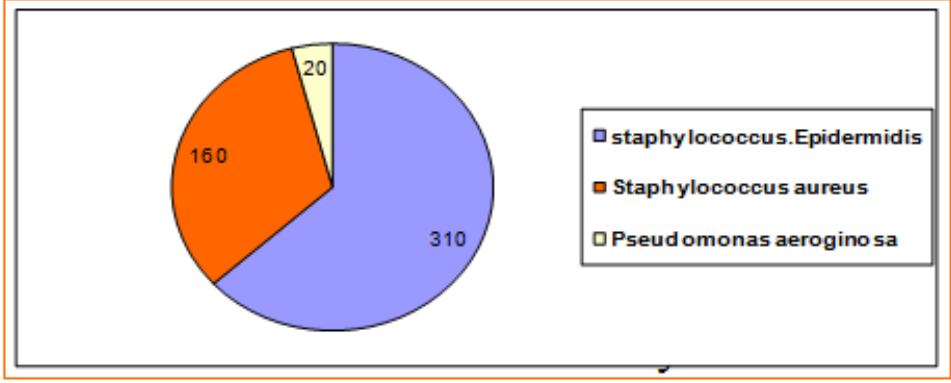

Bacterial growths

Figure No 8

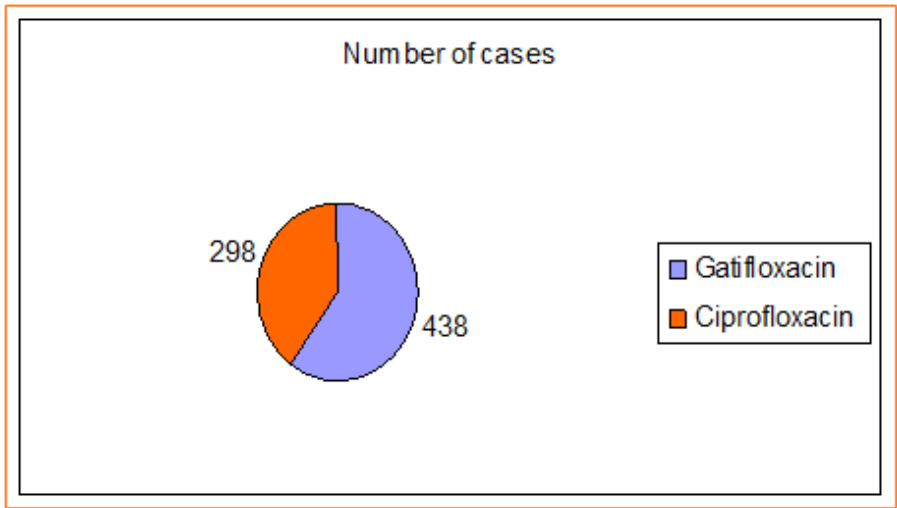

Antibiotic sensitivity

\section{Conclusion}

Preponderance of farmers and stone workers from rural areas was found. Male patients were significantly more. Young and middle aged persons were affected more frequently. Trauma with stick and stone particles was an important cause. Most of the cases were bacterial keratitis followed by fungal keratitis. Staph.epidermidis and Staph.aureus were common bacteriological agents. Early management of patients with microbiological support gave satisfactory results. Gatifloxacin is more effective than ciprofloxacin

\section{References}

[1]. The prevention of blindness: report of a WHO Study Group. Geneva, World Health Organization, 1973: 10-11 (WHO Technical Report Series, No. 518). 2. Global initiative for the elimination of avoidable blindness. Geneva, World Health Organization, 1997 (unpublished document WHO/PBL/97.61/Rev 1). Br J Ophthalmol 1997;81:965-971 doi:10.1136/bjo.81.11.965

[2]. Schaefer F, Bruttin O, Zografos L, et al. Bacterial keratitis: a prospective clinical and microbiological study. Br $\mathrm{J}$ Ophthalmol 2001;85:842-7.

[3]. Clinical Ophthalmology a systematic approach by Jack J Kanski Sixth Edition

[4]. Diseases of the eye Parsons twentieth edition 
[5]. Upadhyay MP, Karmacharya PC, Koirala S, Tuladhar N, Bryan LE, Smolin G, et al.(1991) Epidemiologic characteristics, predisposing factors, and etiologic diagnosis of corneal ulceration in Nepal. Am J Ophthalmol 111:92-99.

[6]. Di Bisceglie AM, Carmichael TR (1987) Factors predisposing to central corneal ulceration in a developing population. S Afr Med J 71:769-770

[7]. National Committee for clinical standards performance, standards for antibiotic susceptibility testing international supplement NCCLs committee for clinical laboratory standards waney $11^{\text {th }}$ edition 2001

[8]. Asbell P, Stenson S. Ulcerative keratitis. Survey of 30 years' laboratory experience. Arch Ophthalmol. 1982 Jan; 100(1):77-80.

[9]. Suppurative Keratitis: A laboratory manual and guide of microbial ketatitis. By A. K Leck, M. M. Matheson, J. HeritageBaum JL. Initial therapy of suspected microbial coneal ulcers. I. Broad antibiotic therapy based on prevalence of organisms. Surv Ophthalmol. 1979 Sep-Oct;24(2):97-105.

[10]. Jones DB. Initial therapy of suspected microbial corneal ulcers. II. Specific antibiotic therapy based on corneal smears. Surv Ophthalmol. 1979 Sep-Oct;24(2):97-116.

[11]. Baker RS, Flowers Jr CW, Casey R, et al. Efficacy of ofloxacin vs cefazolin and tobramycin in the therapy for bacterial keratitis. Arch Ophthalmol 1996;114:632-3

[12]. Bennett HG, Hay J, Kirkness CM, et al. Antimicrobial management of presumed microbial keratitis: guidelines for treatment of central and peripheral ulcers. Br J Ophthalmol 1998; 82:137-45.

[13]. Gudmundsson OG, Ormerod LD, Kenyon KR, et al. Factors influencing predilection and outcome in bacterial keratitis. Cornea 1989; 8:115-21.

[14]. Wilhelmus KR, Hyndiuk RA, Caldwell DR, et al. 0.3\% Ciprofloxacin ophthalmic ointment in the treatment of bacterial keratitis. The Ciprofloxacin Ointment/Bacterial Keratitis Study Group. Arch Ophthalmol 1993; 111:1210-18.

[15]. O'Brien TP, Maguire MG, Fink NE, et al. Efficacy of ofloxacin vs cefazolin and tobramycin in the therapy for bacterial keratitis. Report from the Bacterial Keratitis Study Research Group. Arch ophthalmol1995; 113:1257-65.

[16]. Coster DJ, Badenoch PR. Host, microbial, and pharmacological factors affecting the outcome of suppurative keratitis. Br J Ophthalmol. 1987 Feb;71(2):96-101.

[17]. Gudmundsson OG, Ormerod LD, Kenyon KR, Glynn RJ, Baker AS, Haaf J, Lubars S, Abelson MB, Boruchoff SA, Foster CS, et al. Factors influencing predilection and outcome in bacterial keratitis.Cornea. 1989;8(2):115-121.

[18]. Borrmann LR, Leopold IH. The potential use of quinolones in future ocular antimicrobial therapy.Am J Ophthalmol. 1988 Aug $15 ; 106$

[19]. Mahajan VM (1985) Ulcerative keratitis: an analysis of laboratory data in 674 cases. J Ocul Ther Surg 4:138-141.

[20]. Hagan M, Wright E, Newman M, Dolin P, Johnson G (1995) Causes of suppurative keratitis in Ghana. Br J Ophthalmol 79:10241028 .

[21]. Liesegang TJ, Forster RK (1980) Spectrum of microbial keratitis in south Florida. Am J Ophthalmol 90:38-47. 